\title{
LÓGICA OCHAMISTA, LÓGICA ANTIOCKHAMISTA: PRINCIPALES CUESTIONES EN CONTROVERSIA ${ }^{1}$
}

Carolina Julieta Fernández (UBA CONICET) ${ }^{2}$

carolinajfernandez@gmail.com

Resumo: Este trabajo es un análisis comparativo de la Logica Campsale Anglici, valde utilis et realis contra Ocham, de autor anónimo vulgarmente conocido como pseudo Ricardo de Campsall, y la Summa logicae de Guillermo de Ockham, en respuesta a la cual fue redactada. Se reseñan las posiciones fundamentales de ambos autores respecto de cinco cuestiones paradigmáticas: la sinonimia entre términos abstractos y concretos, la referencia de las primeras y segundas intenciones, la naturaleza de las relaciones de predicación en las proposiciones, el estatus de las pasiones del alma y el significado primario de las voces. El objetivo es caracterizar la polémica entre nominalismo y realismo en la segunda década del s. XIV.

Palavras-chave: nominalismo, realismo, Ockham, Pseudo Campsall.

En el panorama de las primeras décadas del siglo XIV aparecen expresiones de lo que puede considerarse como un prenominalismo respecto de diversas cuestiones puntuales de los debates filosóficos -Enrique de Harclay o Pedro de Auriole, por poner algunos casos-, pero se reconoce que la reacción más terminante y sistemática contra el pensamiento realista en su conjunto, y quizá la construcción de la

\footnotetext{
${ }^{1}$ Recebido: 30-11-2010/Aprovado: 25-03-2011/Publicado on-line: 07-09-2011.

${ }^{2}$ Carolina Julieta Fernández é Professora-adjunta do CONICET, Sección de Estudios de Filosofía Medieval, Instituto de Filosofía, Facultad de Filosofía y Letras, Buenos Aires, Universidad de Buenos Aires, Argentina.
} 
imagen del "realismo" como una corriente u orientación filosófica unificada más allá de las divergencias entre sus adherentes, fue encarnada por Ockham. A su vez, entre las primeras reacciones realistas contra las críticas de Ockham se cuenta la de Walter Burley, en cuyo propio pensamiento Ockham parece haber motivado profundos cambios (CONTI 1990), pero se destaca, asimismo por su sistematicidad y globalidad, un texto de autor anónimo, la Logica Campsale Anglici, valde utilis et realis contra Ocham (SYNAN 1968). La atribución de esta obra a Ricardo de Campsall, graduado como maestro de artes en Oxford en 1305, se ha demostrado falsa mediante la confrontación con otras fehacientemente suyas. Podría tratarse de Juan de Reading o de Walter Chatton, ambos franciscanos, seguidores de Duns Escoto y enfrentados a Ockham; sin embargo, la identidad del autor permanece deliberadamente oculta, siendo, en todo caso, probable que Chatton inspirara y supervisara su trabajo. La Logica contra Ockham es una refutación capítulo por capítulo del primer libro de la Summa logicae de Ockham (BOEHNER et alii 1974). Ambas obras fueron redactadas en el mismo ambiente y con muy poco tiempo de diferencia: Londres, ca. 1323. Lo que sigue es una reseña de las respectivas posiciones de Ockham y el ps. Campsall en torno de cinco cuestiones fundamentales, a través de la cual se puede bosquejar cuáles son las opciones filosóficas en juego.

\section{REFERENCIA DE LOS CONCEPTOS CONCRETOS $\mathrm{Y}$} ABSTRACTOS.

La primera cuestión es si, de los conceptos de substancias, los concretos y sus correspondientes abstractos (vg., "hom- 
bre" y "humanidad"; "caballo" y "equinidad") son o no sinónimos, por más que los nombres que les corresponden en el lenguaje sean distintos. El debate sobre el significado de los concretos y los abstractos se enmarca en la cuestión más general de la sinonimia en el lenguaje mental, es decir, la cuestión de si a todas las variaciones de los términos hablados y escritos les corresponden parejas variaciones de los términos mentales, cuestión sobre la cual nuestros autores mantienen pocos acuerdos y varios desacuerdos. La distinción entre un doble orden conceptual, por una parte, y hablado y escrito, por la otra, vg., un lenguaje mental y múltiples lenguas empíricas de comunicación, da origen a un sinnúmero de discusiones en esta época y, en ese sentido, su aceptación es generalizada. También hay acuerdo, entre ambos autores, en que es precisa una concordancia de criterios de verdad entre ambos lenguajes (vg., la misma proposición no puede ser verdadera en la mente y falsa en la voz) y en que, así como el orden conceptual guarda prioridad respecto del lingüístico, así el orden real, respecto del conceptual (vg., si una pluralidad de voces no obedece más que al afán de hermosear lo que se dice, su correlato mental podrá ser reducido tanto cuanto lo permita la necesidad de significación, y esta última, a su vez, se satisfará una vez que traduzca en proposiciones mentales tantas cosas, ni más ni menos, cuantas hay en el orden extramental). He aquí un extracto de la discusión:

OCKHAM (apud BOEHNER et alli 1974, 23-29):

Aristoteles opinaba que ninguna cosa imaginable se importa por el nombre 'hombre', que no se importe, del mismo modo, por el nombre 'humanidad' y viceversa, pues, según él, ninguna cosa hay aquí abajo, excepto la materia y la forma o el compuesto o el accidente [...]. Y si se dijera que Sócrates supone por un compuesto de naturaleza y diferencia individual, el cual sustenta la naturaleza, esto no es válido, pues
PS. CAMPSALL (apud SYNAN 1968, 2-5):

[...] si [...] hubiera un compuesto a cuya composición concurrieran la materia y la forma sensitiva, por otro lado, de tal concurso resultaría la forma del todo, que se distinguiría formalmente de esas dos, tomadas simultáneamente. [...] Ahora bien, ese todo que incluye esas dos partes y la forma del todo podría ser importado por el término 'un animal', pues a cualquier cosa formalmente distinta de otra le acontece 
como se muestra más abajo, no hay tal compuesto. [...] De lo que se sigue que todas estas proposiciones: 'Todo hombre tiene la humanidad', 'Toda humanidad está en el hombre', 'Todo animal tiene la animalidad' y semejantes, en sentido propio, esto es, según la propiedad de la expresión, son falsas. que se le imponga un nombre distinto [...], y entonces, el término que significa esa forma en abstracto será el término 'animalidad' [...]. En cambio, el término que importa ese compuesto y la forma del todo será el término 'hombre', y entonces otra vez, como antes, se puede abstraer esta forma del todo, y ese término, que la significa así, en abstracto, será 'humanidad', y como aquello que se importa por los términos 'hombre', 'humanidad', por sí, no es individual y singular [...], es necesario que sea contraído a cierto individuo por algo formalmente distinto $[\ldots]$.

La respuesta de Ockham, como se ve, es positiva: según él, los conceptos abstractos del mencionado tipo son sinónimos de sus correspondientes concretos, de tal modo que no significan nada distinto que aquéllos (por lo cual son intercambiables en la misma proposición mental, así como son predicables recíprocamente), y no difieren de ellos más que en cuanto a la expresión lingüística. "Humanidad" no significa ni más ni menos realidades que "hombre": ambos conceptos significan todo cuanto de real hay en el compuesto humano exceptuando los accidentes, a saber, cuerpo, alma y el compuesto de ambos, que no es alguna entidad adicional a dichas partes esenciales. Sócrates no es supósito de la humanidad, como si ésta precisara de una diferencia individual para concretizarse; de ahí que sea falso decir "La humanidad está en Sócrates" o "Sócrates sustenta la humanidad". Claro que, desde el punto de vista teológico, existe cuando menos un caso en el cual será verdad decir que la humanidad es sustentada por algún supósito: en la persona de Cristo, la humanidad es sustentada por la segunda persona de la Trinidad, y tal único caso es suficiente, si bien sólo loquendo theologice, para falsear la proposición "Todo hombre es humanidad" y volver verdadera la proposición "Algún hombre no es humanidad". Como dice Spade, puesto que según la teología Cristo no es su huma- 
nidad, sino que la tiene, se sigue que si el número de hombres es $n$, entonces el número de humanidades también es $n$, pero los hombres y las humanidades juntos suman $n+1$ entidades distintas, no n ni n2" (Spade 1990, 105).

La respuesta del ps. Campsall a la misma cuestión es, en cambio, negativa: los conceptos abstractos del mencionado tipo no son sinónimos de sus correspondientes concretos, por lo cual difieren de ellos tanto en la mente como en la expresión lingüística. "Humanidad" significa una entidad formalmente distinta de "hombre", la cual resulta del concurso de las partes esenciales del compuesto pero es irreductible a la pura conjunción de ambas, y, sin embargo, no constituye algo real, sino sólo formalmente nuevo, adviniente al producirse su unión. Dicha entidad formal es llamada "forma del todo" (forma totius), la cual puede ser objeto de una abstracción intelectual y constituye el significado del concepto de "humanidad". No siendo, por sí misma, ni universal ni individual, pues no le repugna estar en muchos, la humanidad precisa ser contraída a un individuo determinado, y tal será su supósito. En efecto, el individuo concreto es susceptible de una suerte de desagregación metafísica que puede ejemplificarse así: "cuerpo + alma sensitiva + animalitas o forma animalitatis = animal; animal + alma intelectiva + humanitas o forma humanitatis $=$ hombre; hombre + diferencia individual o sorteitas $=$ Sócrates". "Humanidad" es el nombre de aquella entidad formal, en tanto que "hombre" lo es de la conjunción de ésta y sus partes esenciales; de ahí que, según este autor, ambos términos no sean sinónimos. Sin embargo, tanto "hombre" como "humanidad" significan en primer término la naturaleza común, con la diferencia de que "hombre" también significa, en sentido derivado, los hombres singulares (Sy- 
nan 1968, 29. 07-08; 40. 06, 223-224). Como se ve, el núcleo del desacuerdo entre Ockham y su impugnador es la doctrina de la distinción formal de Duns Escoto, a quien el segundo manifiesta seguir en esto. La argumentación del ps. Campsall consiste esencialmente en defender, contra las críticas de Ockham, la noción de una distinción formal a parte rei: por medio de dicha distinción, considera posible postular una naturaleza a la cual, según su repetida expresión, "no le repugna" estar en muchos porque no le compete por sí misma ser una ni múltiple, ser la misma o ser diversa -donde la referencia obligada es, por intermedio de Duns Escoto, Avicena (Ib. 15. 23; 6. 12. y 15. 06; 14. 09. 15. 11). Dicha naturaleza puede ser determinada por una diferencia numérica de la cual no se distingue realmente. Por eso mismo, naturaleza y diferencia numérica no conforman un compuesto: porque no se distinguen realmente al modo en que, por ejemplo, se distinguen la materia y la forma como partes reales de los entes compuestos. El recurso a la distinción formal permitiría a ps. Campsall salvarse, así, de una de las principales objeciones de Ockham: que postular semejante naturaleza común equivaldría a postular la inmanencia de algo único en muchas cosas (Ib. 13. 13). No tratándose de realidades distintas, sino de "razones formales", pueden ser incluidas en el singular una pluralidad de determinaciones y relaciones, sólo la última de las cuales es la singularidad (Ib. 13. 10; 15. 21).

\section{TÉRMINOS DE PRIMERA Y SEGUNDA IMPOSICIÓN E INTENCIÓN.}

Un segundo punto de controversia es cómo interpretar la distinción entre términos de primera y segunda imposición 
e intención. Se trata de una de las varias polémicas a que dio lugar la tradicional discusión sobre el estatus de los géneros y especies, en lo que, para evocar la célebre noción de A. de Libera, constituye un gran complejo de "preguntasrespuestas”, disciplinas, obras y autores. El marco general, de todos modos, lo proporcionó la lógica: esta ciencia venía sufriendo una compleja evolución desde el surgimiento de la lógica terminista, con la teoría de las propiedades de los términos, los aportes de los lógicos medievales a la lógica aristotélica nueva, cuyo gran transmisor fue Alberto Magno, y las teorizaciones sobre los términos sincategoremáticos. La lógica medieval propiamente dicha contenía numerosos elementos de potencial desarrollo teórico: la preocupación por dar cuenta de la articulación del discurso lógico hasta en sus más finos elementos, como los términos sincategoremáticos (análogos a las modernas constantes lógicas), se manifestó ya en los primeros lógicos, como Guillermo de Shyreswood; la distinción entre un término que supone por los individuos actualmente existentes y el que supone por todos los individuos futuros se manifestaba ya en los tratados De ampliatione; la distinción entre el término que significa cierta naturaleza común y el que significa los individuos tenía una formulación madura ya en los tempranos tratados de Walter Burley (BOEHNER 1950). Puntualmente, la conexión entre la noción de intentio y la ciencia lógica fue establecida con la recepción de la doctrina aviceniana de la lógica como ciencia de las "intenciones segundas", que implicó el triunfo de una concepción fuertemente intelectualista de la lógica por sobre una previa concepción de dicha ciencia como estudio de puros fenómenos lingüísticos (PINI 2002, 22ss.; Panaccio 1999, 273). Dentro de este marco, los autores acuerdan en identificar la noción de im- 
posición (impositio) con las lenguas de comunicación surgidas por arbitrio de los hablantes y la noción de intención (intentio), con los contenidos mentales, mientras que disputan sobre las diversas relaciones entre éstos y la realidad extralingüística y extramental. La polémica se resume en los siguientes términos:

OCKHAM (BOEHNER et alli 1974, 43-44):

[...] intención es algo en el alma que es un signo naturalmente significativo de algo por lo que puede suponer o que puede ser parte de la proposición mental. Ahora bien, tal signo es doble. Uno, el que es signo de una cosa que no es $\langle a$ su vez> un signo semejante, signifique tal signo junto con éste o no, y a eso se llama primera intención, tal como es aquella intención del alma que es predicable de todos los hombres, y similarmente, la intención predicable de todas las blancuras y negruras, y así con otras cosas. [...] En cambio, la segunda intención es aquella que es signo de tales primeras intenciones [...]. Por eso, así como los nombres de segunda imposición significan por convención nombres de primera imposición, asimismo la segunda intención significa naturalmente la primera, y así como el nombre de primera imposición significa otra cosa que nombres, asimismo la primera intención significa otras cosas que intenciones.
PS. CAMPSALL (SYNAN 1968, 11.03-06. La cursiva es nuestra):

[...] el intelecto, al ver un individuo de una especie, por ejemplo, Sócrates, puede, sin discurrir alguno, causar un concepto que es importado o expresado por el término 'Sócrates' y otro que es expresado por el término 'hombre'. Pero después, viendo, el intelecto que esos dos se distinguen, comienza a preguntar cómo y de qué manera se distinguen y, al buscar las causas, finalmente encuentra que la razón formal de aquello que se importa por 'Sócrates' no le repugna a ningún individuo de la especie humana, de tal modo que por sí no pueda convenirle, a menos que la repugnancia venga desde afuera: pero ve que le repugna por la diferencia individual, con la cual es realmente idéntico, y entonces el intelecto forma esta proposición: que a esa cosa, bajo tal orden al intelecto -esto es, bajo su razón formal, la cual el intelecto concibe distintamente-, no le repugna convenir a muchos individuos, y entonces, a esa cosa así considerada le impone el nombre 'especie', término que importa esa cosa, bajo esa relación. [...] Por esto es manifiesto que dicen algo falso lo que dicen quienes dicen que las primeras y segundas intenciones difieren en tanto que las primeras significan cosas externas mientras que las segundas, intenciones, conceptos o cosas en el alma. Pues es manifiesto que tanto las primeras como las segundas significan cosas externas, de un modo y otro.

Según Ockham, la distinción entre términos de primera y segunda imposición e intención equivale a la distinción entre términos que están por su significado y términos que están por sí mismos, comparable con la distinción entre uso y mención o lenguaje y metalenguaje. Esta distinción se duplica al aplicarse tanto a los términos mentales o "intenciones" como a los hablados y escritos. Prolija y sistemática, la clasificación de Ockham abunda en acepciones 
amplias y estrictas, originadas en la posibilidad, por lo pronto, de que un signo no signifique una cosa, sino otro signo, y además, que el signo pueda ser significado, tanto en su doble dimensión cósica, como en su dimensión significativa, doble dimensión de la que gozan, otra vez, tanto los signos naturales como los convencionales. Por ejemplo, Ockham señala que, dado que la mayoría de los nombres instituidos por los gramáticos para significar las partes de la oración hablada y escrita son aplicables a las partes del lenguaje mental (tesis culminante de su "nominalismo", y con él, de la filosofía medieval del lenguaje, según la conocida interpretación de Panaccio, 1999), en sentido amplio pueden ser llamados "de segunda imposición" tanto los verbos, conjunciones, etc., mentales, como sus contrapartes hablados y escritos, aunque en sentido estricto lo sean sólo los segundos. Inversamente, en sentido amplio pueden ser clasificados como "de segunda intención" los nombres que significan, indistintamente, intenciones del alma en su condición de signos naturales y signos arbitrarios (por ejemplo, "género", "especie", "universal" o "predicable" pueden estar, tanto por intenciones del alma como por palabras escritas o habladas); mas en sentido estricto sólo se aplica esta clasificación a los primeros. Asimismo, Ockham dice que, puesto que todo aquello que no es nombre de segunda imposición (es decir, nombre instituido por los gramáticos para significar las partes de la oración en tanto que significativas) es nombre de primera imposición, quedarán incluidos entre estos últimos tanto aquellos nombres que se instituyeron para designar cosas que no son signos -a saber, nombres de primera intención-, como aquellos que se instituyeron para designar intenciones del alma en tanto que signos naturales -a saber, nombres de segunda inten- 
ción (Boehner et alli 1974, 38-41). De modo semejante, Ockham señala la prioridad de los términos significativos o categoremáticos y sólo en sentido amplio considera que puede atribuirse a los términos cosignificativos o sincategoremáticos todas las propiedades de los primeros, como si fueran "arrastrados" por éstos. Se trata de otra de sus tesis decisivas, en la perspectiva de los analistas: Ockham giró, desde una temprana interpretación de los términos sincategoremáticos como representaciones imaginarias de palabras exteriores, a una posterior equiparación de éstos con los términos categoremáticos en cuanto a su estatus de signos naturales. Esto implicó un paso más, entre otros dados por el mismo Ockham, hacia una concepción lingüísticosignificativa de lo mental en detrimento de una concepción representacionalista (tabarroni, 1982; panaccio, 1999). Más allá de las sutilezas de esta clasificación, lo que resalta, ante todo, es la extrapolación de muchos de los problemas metafísicos tradicionales desde el ámbito de la ontología al estricto ámbito de la semántica y la sintaxis de los términos y las proposiciones. Por otra parte, la unificación sistemática de todo lo que ampliamente puede entenderse como término -los términos artificiales y los naturales, significativos y cosignificativos, de significado estricto y amplio, y de primero y segundo orden-, todos ellos, bajo una misma noción sintáctico-semántica: la reducción de todos a signos en sentido puro. La consecuencia de esta sistematización, respecto a los términos de segundo orden (tanto los de segunda imposición como los de segunda intención), es que son, respectivamente, palabras que significan palabras y conceptos que significan conceptos. Otra cuestión, colateral pero decisiva, es cómo se justifica en el esquema ockhamista la diferencia entre términos de primera imposición menos y 
más universales (vgr., "hombre" y "animal"): no por una conveniencia mayor o menor de los individuos en algo, sino por las mayores o menores similitudes entre los individuos y por la capacidad del concepto para ser predicado, correspondientemente, de un número mayor o menor de individuos (Ib. 63), ya que es en éstos que "se termina" inmediatamente la intelección universal (Ib. 124).

El autor de la lógica antiockhamista afirma, en cambio, que los términos de segunda imposición y segunda intención significan realidades extramentales tanto como los de primera imposición e intención, y rediseña la clasificación de Ockham. Afirma que la obtención de los conceptos universales (v. gr., "hombre") es inmediata y simultánea con la de los propios ("Sócrates"), ambas causadas por el objeto externo; mas por vía de una comparación que el intelecto efectúa entre esos conceptos, ambos de primera intención, llega a concebir distintamente una pluralidad de realidades formales, a muchas de las cuales no les repugna, por sí mismas, estar en muchos, y a las cuales impone nombres como "especie", "género", etc. Los llamados "términos de segunda intención" no significan, pues, conceptos que, a su vez, significan individuos, sino que significan esas diversas realidades -sólo que con prescindencia de toda relación al intelecto en el caso de los de primera intención y con intervención del intelecto, en el de los de segunda (Synan 1968, 11. 03-06). Asimismo, desde esta perspectiva la diferencia entre los conceptos genéricos y específicos encuentra su verdadera justificación: "hombre" y "animal" no se diferencian por predicarse respectivamente de menos y más individuos, sino porque importan diversas realidades en las que convienen respectivamente menos y más individuos (Ib. 4 y 19). Los conceptos de segunda intención ("especie", 
"género", etc.), en la medida en que no se dan sin una cierta comparación o discurso del intelecto, no significan propia ni solamente la naturaleza común extramental, ni (contra Ockham) un puro, desnudo concepto, sino aquella realidad común en tanto relacionada con una actividad del intelecto (Ib. 11.03; 15. 15). El ps. Campsall reivindica la teoría escotista de las segundas intenciones, que era, a su vez, una revisión de la teoría de Tomás de Aquino a la luz de críticas de autores intermedios como Simón de Faversham o Radulphus Brito, en una polémica cuyo punto central era, otra vez, si las segundas intenciones resultaban de una comparación entre puros conceptos o entre algún tipo de realidades (PINI, 2002).

\section{NATURALEZA DE LAS RELACIONES DE PREDICACIÓN EN LAS PROPOSICIONES.}

El tercer punto en discusión concierne a las estructuras proposicionales y su relación con lo real. Hay acuerdo generalizado en que la proposición tiene una triple sede -escrita, hablada y mental- y en que, por añadidura, la tendrán también sus componentes, según la enseñanza boeciana. Hay acuerdo, también, en que la proposición constituye un cierto tipo de composición y estaría, en ese sentido, estrechamente asociada con las nociones de verdad y falsedad que, según la enseñanza aristotélica, no son de lo simple, sino de lo compuesto. Pero existe controversia, entre otras cosas, sobre la naturaleza de los términos que componen la proposición (principalmente la mental, ya que ésta tiene una reconocida prioridad sobre la hablada y escrita), sobre sus relaciones al interior de ésta y en qué sentido dichas relaciones son algo de la realidad. Para el momento 
en que estas dos sumas son redactadas, se encuentra en franco desarrollo el proposicionalismo, es decir, la tendencia o derivación general de la lógica terminista a estudiar los términos de manera contextual, como partes de la proposición; en cuanto al realismo proposicional $y$, particularmente, a la tesis de que el significado de la proposición es algo más que el significado de los términos de la misma, esta tradición tenía importantes antecedentes en Duns Escoto y en el temprano Walter Burley, artífice, ya en 1310, de la tesis central de la propositio in rebus (CESALLI, 2007). Las respectivas posiciones de nuestros autores se resumen en lo siguiente:

OCKHAM (BOEHNER 1974, 260):

Para la verdad [...] de la proposición [...] no se requiere que el sujeto y el predicado sean realmente lo mismo, sino que se requiere que el predicado suponga por todas aquellas cosas por las que supone el sujeto, de tal modo que se verifique de ellas.
PS. CAMPSALL (SYNAN 1968, 18.02):

[...] la predicación es real y [...] la cosa externa se predica o es sujeto tan verdaderamente como la palabra o el concepto -lo cual no ha de decirse sino hablando metafórica e impropiamente, tomando 'predicación por cierta unión real de aquellas cosas por las que suponen los términos de las proposiciones $[\ldots .$.$] .$

La doctrina ockhamista es que la proposición se compone de conceptos, los cuales tienen, por naturaleza, la capacidad o propiedad de suponer por algo en el contexto de la misma proposición (como se sabe, la suposición es una propiedad del término tomado como parte de la proposición, mientras que, aislado, un término no supone, sino meramente significa), y que la verdad o la falsedad de una proposición se determina por el hecho de que sus términos significativos o categoremáticos (sujeto y predicado) suponen o están por lo mismo -si la proposición es verdadera- o no -si es falsa-, pudiendo ser ello cosas externas, contenidos mentales o entes lingüísticos pero debiendo distinguirse, en todo caso, cuándo el término supone por aquello que significa primariamente (está en "suposición personal") y 
cuándo, por el contrario, supone por algo que significa sólo de modo derivado (está en suposición "simple" o "material"). El objeto inmediato del saber científico no son las cosas, sino la proposición verdadera -y, más propiamente, la universal y necesaria; por ende, sólo aquella cuyos términos son generales-, pero no están, las cosas mismas, llamadas a integrar las proposiciones, por lo cual no se define la verdad de éstas como identidad entre sus términos/cosas, sino como identidad de aquello por lo cual los términos suponen.

Atañe a este punto una de las críticas más frecuentes de la suma antiockhamista: que Ockham pretende salvar todo mediante puros signos conceptuales y propiamente lingüísticos, cuando en verdad éstos se subordinan a las cosas por las que suponen -y no menos los universales que los singulares. De ahí que ps. Campsall insista a lo largo de su obra en que los términos acuñados por la tradición filosófica para clasificar la realidad -principalmente, los cinco universales de Porfirio y las categorías de Aristóteles- deben ser entendidos antes como cosas que como conceptos o palabras. "Género", “especie”, “diferencia”, "propio", "accidente" no designan, primero, signos mentales, sino cosas (Ib. 18.02; 19; 21.02-3; 21.05; 22.03-4; 23.01-02; 24.0305): "animal", "hombre", "racional”, "capaz de reír", "blanco" son conceptos, sí, mas a causa de que importan algo en la realidad, y entonces será a ello que deban atribuirse primariamente esos nombres. Por todo esto, así como la predicación que se da en las proposiciones compuestas de voces depende de la que se da en las proposiciones compuestas de conceptos, proporcionalmente, éstas últimas corresponden y siguen a cierta "proposición in re" de cuya verdad dependen tanto la proposición mental, como la vocal, entendiendo, por tal "proposición in re", no más que 
una expresión metafórica, en el sentido de una unión metafísica de naturalezas más o menos comunes, sólo formalmente distintas entre sí y respecto del individuo en el cual están. Usando a su favor un recurso ockhamista (en sus comentarios a la Física de Aristóteles, Ockham suele decir que el Filósofo a veces habla logice en una obra como la Física, que es una scientia realis, y por eso usa un término en suposición simple y no en suposición personal), ps. Campsal dice que Aristóteles frecuentemente habla en sus libros lógicos como físico, de ahí que, si habla de la sustancia segunda como de un concepto, lo hace sin aclarar que está usando el término en sentido derivado, aunque en sentido propio, de virtute sermonis, dicho término signifique una res. Se trata de la inversión exacta de un recurso ockhamista: aplicando de modo inusualmente sistemático el viejo recurso de distinguir entre uso propio y translativo de un mismo término, Ockham solía interpretar que Aristóteles entiende los términos "sustancia segunda", "género", "especie" y la gran mayoría de sus predicamentos como conceptos de la mente. Si a veces parece que pensara en ellos como realidades -solía decir-, se debe a que no hay un término lingüístico distinto para referirse al concepto y a las realidades que éste significa, y el Filósofo omitió aclarar que hacía un uso translativo y no un uso propio (SYNAN (1968), $13.11 ; 18: 02-05)$.

\section{STATUS DE LOS CONCEPTOS IN ANIMA.}

Los dos últimos puntos de controversia forman parte de la discusión tardomedieval sobre el triángulo semántico aristotélico delineado en el célebre comienzo del De Interpretatione. El primero concierne al lado gnoseológico 
del triángulo: la relación "pasiones del alma" - cosas. El centro de la discusión estaba en cómo caracterizar esas "pasiones del alma" desde el punto de vista psicológico (era particularmente problemático, en este sentido, el hecho de que Aristóteles las hubiera calificado de ese modo, por sus connotaciones aparentemente pasivas, y por eso asociadas con las funciones sensibles del alma) y en cómo interpretar su relación de semejanza con las cosas extramentales. Para la segunda década del siglo XIV, el panorama de la discusión era muy complejo: desde el último cuarto del siglo XIII se había ensayado descosificar algunos aspectos de lo mental para garantizar que la tesis de una "in-existencia" intencional o inmanencia de lo conocido en la mente no se volviera un obstáculo al conocimiento del mundo externo, pero garantizar, al mismo tiempo, la estabilidad de las proposiciones. La introducción de objetos mentales, entes de razón o figmentos había sido un paso en ese sentido, pues, haciendo de ellos el objeto inmediato de los actos intelectuales, se prescindía del compromiso ontológico de existencia de los individuos. Pero, al mismo tiempo, se agitaba el fantasma del internalismo, contrario al ideal unánime de explicar cómo la mente accede al mundo externo mismo, y surgía una corriente de oposición y defensa de la referencia externa directa, especialmente en el ambiente franciscano. Como parte de este complejo de "problemas-respuestas" hay que contar, asimismo, la teoría clásica de las especies inteligibles y las críticas avanzadas desde el lado franciscano (Tachau 1988; Spruit 1994; panaccio 1999). En el marco de esta discusión, nuestros dos autores entienden la relación entre conceptos del alma y cosas del siguiente modo: 
OCKHAM (BOEHNER et al. 1974, 43 y 48-49):

[...] qué es aquello en el alma que es un signo semejante? Hay que decir que sobre este tema las opiniones son diversas. Algunos dicen que no es sino algo representado por el alma. Otros, que es una cualidad realmente existente en el alma, distinta del acto de entender. Otros dicen que es el acto de entender. [...] Pero sobre estas opiniones se investigará después; por eso por ahora baste que la intención es algo en el alma, que es signo naturalmente significativo de algo, por lo cual puede suponer o que puede ser parte de la proposición mental.
PS. CAMPSALL (SYNAN 1968, 11.02):

[...] ninguna cosa distinta del intelecto, al menos en esta vida, puede estar, por sí <misma>, suficientemente presente al mismo intelecto [...]. [...] es necesario, entonces, que se haga presente al intelecto por alguna otra cosa; mas ello es la especie causada por el objeto mismo: mas esa especie representa verdaderamente esa cosa y es apta para suponer por ella en la proposición mental. Y el intelecto la usa componiendo o negando algo de ella, como <si fuera> la cosa misma. Si, pues, estuviera presente, se diría y usaría, y por eso, tales especies a veces se llaman 'similitud de la cosa', a veces, 'intención' -pues por ella tendemos a otra cosa, por caso, al objeto-, no porque sea el acto de entender, sino porque, mediante ella, entendemos la cosa, y por alguno es llamada 'ídolo', y 'cosa puesta en el ser intencional', y esta especie informa tan verdadera y tan realmente el alma como la blancura, la pared.

Como se ve, por parte de Ockham, vemos consideradas aquí tres variantes teóricas: una, que los universales sean objetos ficticios, entes de razón con un ser puramente intencional -v. gr., no verdaderos entes, esto es, ni cualidades ni sustancias; por lo tanto, ni actos ni hábitos-, a los que tiende o en los que se termina el acto intelectual. Otra, que sean cualidades, tan reales como cualquier cualidad de un objeto externo, sólo que informantes del alma, en las que se termine el acto intelectual de tal manera que sólo existan en el alma concomitantemente con éste, mas realmente distintas de él. Tercero, que no haya cualidades tales generadas concomitantemente a los actos intelectuales, sino que las pasiones, conceptos, etc., sean los actos mismos que informan realmente al alma. Como se sabe, a lo largo de su carrera Ockham dio un giro desde una temprana adhesión a la primera teoría de los entes de razón como respuesta "más probable" a la cuestión (en su primera versión de la Ordinatio), pasando por una etapa intermedia, en que consideró que dicha teoría y la de los actos mentales o intelecciones eran, por igual, probables (en el proemio a su 
exposición del De Interpretatione), a un estadio final en el que parece adherir definitivamente a la teoría de la ipsamet intellectio (en sus Quodlibeta y la Summa Logicae). Esta última teoría es netamente extensionalista, en la medida en que los conceptos universales son entendidos como actos mentales que operan como signos naturales, en el alma, de los individuos externos: tanto de los reales, como de los posibles, de modo que no significan nada real común, ni externo ni interno al alma, sino que significan una multiplicidad externa de individuos reales (tomando la significación en sentido estricto) y, más aún, meramente posibles (tomando la significación en sentido amplio), pero de modo indiferenciado, y en ello reside su distinción con respecto a los conocimientos particulares. El camino hacia ésta su última respuesta, en este sentido, no está exento de problemas y hesitaciones, y es de destacar que esta última etapa se considera reflejada de modo ejemplar, precisamente en el texto que estamos considerando y que constituye el objeto de crítica de ps. Campsall: la Summa logicae. Aunque en el pasaje que hemos citado aquí arriba Ockham menciona esas "varias teorías probables", destacando como común a todas ellas la noción de predicabilidad como propiedad sine qua non de los conceptos mentales, en una aproximación ulterior descarta el fictum in esse obiective y la qualitas distinta del acto intelectual, y se pronuncia por las intelecciones mismas como el mejor candidato a ocupar el puesto de las "pasiones del alma” o conceptos. La intelección misma, dice, cumple satisfactoriamente con todos los requisitos que debe cumplir: ser capaz de significar y suponer como parte de las proposiciones mentales. Siendo así, la postulación de otras entidades, reales o ficticias, adicionales a las intelecciones, se vuelve sin sentido por el principio de economía o parsi- 
monia (PANACCIO 1999).

Ps. Campsall ataca el corazón de la doctrina ockhamista al decir que, si los conceptos universales significaran directamente la multitud infinita de los individuos externos reales y posibles, carecerían de una significación determinada (synan 1968, 4. 04-05). En cuanto a su estatus entitativo, el autor afirma que todas las intenciones son "especies" causadas por el objeto extramental correspondiente. Argumenta que es necesario postular esta especie para explicar cómo es posible que después del acto intelectual, por breve que sea, la mente adquiera una disposición positiva y nueva a pensar en ese objeto -disposición que no podría asimilarse a un hábito, puesto que éste, según la clasificación de Aristóteles, constituye una cualidad "difícilmente removible". La especie, en síntesis, no es el acto intelectual; tampoco el hábito; mas tampoco un objeto mental ficticio o aparente, sino una cualidad real o subjetivamente presente en el alma, causada por las cosas en el intelecto y remanente en él después de la intelección, la cual sirve como medio de representación de las cosas para el intelecto e inversamente, como medio por el cual éste se dirige a las cosas (SYNAN 1968, 11. 02). El principio rector de la teoría clásica de las especies inteligibles es, precisamente, el señalado por ps. Campsall al comienzo de este pasaje: las cosas mismas no pueden estar en el alma, pues ésta es inmaterial y aquéllas, materiales; es preciso que las cosas externas produzcan o impriman en el alma una cierta representación, especie, imagen o similitud de sí mismas (o, en todo caso, que el intelecto abstraiga activamente esa similitud, a partir de la cooperación de dichas cosas externas). Dicha similitud no debe entenderse como una imagen pictórica en sentido empírico, sino como su esencia 
inteligible, tampoco como el término del conocimiento, sino como un principio instrumental de aquél, que está orientado primariamente a los objetos externos (PINI 1999).

\section{SIGNIFICADO PRIMARIO DE LOS TÉRMINOS VOCALES.}

El último punto, en verdad inescindible del anterior, es el lado semántico del triángulo: la relación voces-pasiones del alma. La teoría según la cual las voces significarían primaria o inmediatamente conceptos, especies o contenidos mentales, y sólo secundaria o mediatamente las cosas mismas, había sido mayoritaria hasta la última década del siglo XIV, cuando se pasó desde una teoría psicologista del significado centrada en las esencias, a una lógico-veritativa centrada en la codificación proposicional de la experiencia. Hay consenso en que el giro fue iniciado por Roger Bacon en 1267 y continuado por Duns Escoto, quien adoptó varias posiciones al respecto en diversas obras (VOS 2006), reseñó las posiciones preexistentes, remontables, cuando menos, 20 años atrás, y produjo un importante giro al pasar de sostener que las voces significan primariamente las especies inteligibles (la posición de Lamberto de Auxerre, Robert Kilwardby, Alberto Magno, el joven Tomás y Simon de Faversham entre 1255 y 1280 aproximadamente, quienes, con distintos matices, no diferencian, al concepto, de la especie o similitud de la cosa en el alma) a sostener que las voces significan primariamente las cosas extramentales, en tanto entendidas, lo cual equivale a decir que significan las esencias universales y abstractas de las cosas en tanto son objeto del acto intelectivo (las posiciones reseñadas por Escoto serían, sin mencionarlos, de Siger de Bravante y del Tomás de 
Aquino maduro). Esta segunda posición implica la distinción entre la especie inteligible y el concepto como el medio o instrumento y el término u objeto del acto intelectivo, respectivamente. Es este último, identificado con el verbo mental, aquello que la voz inmediatamente significa, según la doctrina madura de Tomás de Aquino. En el caso de Escoto, al favorecer esta última teoría de la significación de las cosas extramentales "en tanto entendidas", parece haber sentado de modo claro que las voces significan directa y primariamente algo de la realidad externa y no un objeto mental o ente de razón, dando así un giro con respecto al modelo de Tomás. Fue ese externalismo lo que Ockham terminó de definir, pero con el aditamento de la lisa y llana eliminación de las esencias como realidades extramentales. Para la época de nuestra disputa, una mayoría de autores ha adoptado la teoría de que las voces significan primariamente las mismas cosas significadas por los conceptos, y sólo secundariamente los conceptos mismos. Sin embargo, la posición ockhamista merece, al menos, alguna corrección de ps. Campsall, como se ve en lo que sigue:

OCKHAM (BOEHNER et al. 1974, 8):

[...] las palabras se imponen para significar las mismas cosas que se significan por los conceptos de la mente, de tal modo que el concepto significa primero naturalmente algo, y secundariamente, la palabra significa eso mismo, en tanto que, si ese concepto cambiara su significado, por eso mismo, cambiaría su significado la palabra instituida para significar algo significado por el concepto de la mente, sin nueva institución. [...] Así, la palabra significa naturalmente, como cualquier efecto significa, al menos, su causa; como también el círculo significa el vino en la taberna.
PS. CAMPSALL (SYNAN 1968, 11.10-11):

[...] mal dicen los que dicen que las palabras sólo significan las cosas externas y no los conceptos, porque, como 'significar' no es sino 'conducir al conocimiento de eso', y la palabra necesariamente nos conduce al conocimiento, al menos confuso, del concepto, y no al conocimiento de la cosa, sino mediante el concepto, es manifiesto que la palabra significa naturalmente el concepto y arbitrariamente, la cosa externa.

Según la conocida tesis de la significación directa subordinada de Ockham, signos convencionales y signos mentales palabras y conceptos- pueden significar, ambos, las cosas ex- 
tramentales mismas, sólo que entre ellos existe una ordenación en el sentido de una dependencia: la generación de conceptos en la mente, en el sentido de signos que pueden suponer por su significado en las proposiciones mentales, es independiente de nuestra voluntad, es decir, obedece a una causalidad natural; en cambio, la imposición de los signos lingüísticos está enteramente sometida a nuestro arbitrio. De tal suerte, un cambio en el orden de la voz (por ejemplo, la institución de una nueva palabra) no determinará un cambio en la significación del concepto que le corresponde, mientras que si, por hipótesis, un concepto cambiara de significado, no sería necesario un acto de nueva imposición para que la palabra correspondiente mutara en su respectiva significación. Pero aunque los conceptos son una condición necesaria para que las palabras puedan significar, éstas no son signos primarios o primariamente de los conceptos (BOEHNER et al. 1974, 7-9). Si bien un término significa propiamente cuando supone de modo personal en una proposición de presente $-\mathrm{v}$. gr., cuando traduce en términos lingüísticos o conceptuales un estado de cosas presente-, en un sentido más amplio se considera significativo un término que suponga de modo personal en una proposición real de pasado o futuro, o en una modal: así, la significación de las voces y los conceptos estará a salvo de la hipótesis de aniquilación de clases, y será suficiente con la existencia de un único individuo por cada una (Ib. 95, lin. 1-20).

La crítica de ps. Campsall a Ockham en este punto consiste, por una parte, en restablecer una cierta conexión entre las palabras y los conceptos, que no es la de signos que "suponen por", "equivalen a" o "toman el lugar de" lo significado, sino de indicios o vestigios que llevan, a quien oye, proferirlas, a inferir que conceptos correspondientes 
acompañan, en el alma del hablante, a su pronunciación de dichas palabras. Esta conexión indicial natural entre palabras y pasiones del alma, que fuera señalada por primera vez por Bacon, verosímilmente, no podía ser desconocida por Ockham, quien, cuando menos, la insinúa sin desarrollarla (Ib. 9, lin. 57). Precisamente, es interés de ps. Campsall recuperarla, dándole el papel de única relación significativa que permanecería si, por hipótesis, el concepto dejara de significar el objeto extramental que significa normalmente: ese sería el caso, dice, en que, no significando nada el concepto, la voz no perdería su significación (SYNAN 1968, 1.10-13, 78-79).

Hemos llegado al final de nuestra confrontación entre estas cinco grandes controversias de la lógica ockhamista y su contralógica realista. Los puntos de confrontación que levanta ps. Campsall contra Ockham exceden largamente esta lista; sin embargo, ella es bien representativa de los principales intereses y preocupaciones de este tiempo y ambiente. Vistas globalmente, las estrategias argumentativas de los dos textos son sorprendentemente especulares: el objetor reproduce la del objetado, sólo que invirtiéndola. Así, por ejemplo, es un típico recurso ockhamista afirmar que, en sus comentarios a la Física de Aristóteles, el Filósofo a veces habla logice en una obra como la Física, que es una scientia realis, y por eso usa un término en suposición simple y no en suposición personal. Aplicando de modo inusualmente sistemático el viejo recurso de distinguir entre uso propio y translativo de un mismo término, Ockham solía interpretar que Aristóteles entiende los términos "sustancia segunda", "género", "especie” y la gran mayoría de sus predicamentos como conceptos de la mente. Si a veces parece que pensara en ellos como realidades -solía decir-, se debe a 
que no hay un término lingüístico distinto para referirse al concepto y a las realidades que éste significa, y el Filósofo omitió aclarar que hacía un uso translativo y no un uso propio. Cabe acotar que esta sería la base de la teoría del siglo XIV sobre la virtus sermonis, que originaría las condenaciones de mediados de siglo al ockhamismo en París y sobre la base de la cual se montarían las controversias del siglo XV entre nominalistas y realistas (COURTENAY 1987). Usando este recurso a su favor, ps. Campsal dice que Aristóteles frecuentemente habla, en sus libros lógicos, como físico: de ahí que, si habla de la sustancia segunda como de un concepto, lo hace sin aclarar que está usando el término en sentido derivado, aunque en sentido propio, de virtute sermonis, dicho término signifique una res. Se trata, como se ve, de la inversión exacta de un recurso ockhamista. De modo análogo, en Ockham se verifica un programa antirrealista que se resume en la siguiente regula: si una proposición se verifica por cosas, cuando pocas cosas bastan, en vano han de postularse muchas. Esa es la versión inicial de su novacula, que admitiría una formulación más volcada a la discusión física en las últimas Quaestiones in Physicorum pero permanecería inalterada en esencia). En el contraprograma realista de ps. Campsall se verifica, nuevamente, la inversión de la regla: tantas realidades como sean necesarias (más que las singulares, si es preciso) habrán de postularse para explicar la verdad de una proposición (y quizá sea éste el más fuerte signo de la influencia, si no autoría, de Chatton, a quien se debe originalmente este principio). Evidentemente, semejante comunidad de formas argumentativas, de términos técnicos, de problemas y preguntas, revela la pertenencia a un mismo paradigma, o, al menos, a un ambiente intelectual 
común, probablemente derivado de compartir un mismo studium, y, en ese sentido, es más interesante la articulación de ese paradigma que la controversia de superficie en sí misma.

Abstract: This paper is a comparative analysis of the Logica Campsale Anglici, valde utilis et realis contra Ocham, from an anonymous author known as pseudo Richard of Campsall, and Ockham's Summa logicae, in answer to which the former was written. We summarize both authors's fundamental positions on five key issues: 1) the synonymy between abstract and concrete terms, 2) the reference of primary and secondary intentions, 3) the nature of the relations of predication between terms in propositions, 4) the status of the "passions of the soul" and 5) the prime signification of spoken words. Our aim is to sketch the polemic between Nominalism and Realism in the second decade of the XIVth century.

Key Words: nominalism, realism, Ockham, Pseudo Campsall.

\section{REFERÊNCIAS}

BOEHNER, Ph.; Gál, G.; Brown, S. (eds.). Guillelmi de Ockham Summa Logicae (= SL). In: Venerabilis Inceptoris Guillelmi de Ockham Opera Philosophica et Theologica ad fidem codicum manuscriptorum edita $(=\mathrm{OPh})$. N. Y.: Inst. Franc. Univ. S. Bonaventurae, 1967-1984, v. I, 1974.

. Medieval Logic. An outline of its development from 1250 to c. 1400 . Chicago, 1950.

CESALLI, L. Le Réalisme propositionnel. Sémantique et ontologie des propositions chez Jean Duns Scot, Gauthier Burley, Richard Brinkley et Jean Wyclif. París: Vrin/Sic et Non, 2007.

CONTI, A. D. Ontology in Walter Burley's last commentary on the Ars Vetus. Franciscan Studies, v. 50, p. 121-176, 1990. 
COURTENAY, W. Antiqui and Moderni in Late Medieval Thought. Journal of the History of Ideas, v. 48, p. 3-10, 1987.

PINI, G. Species, concept and things: Theories of signification in the second half of the Thirteenth Century. Medieval Philosophy and theology, v. 8, p. 21-52, 1999.

. Categories and logic in Duns Scotus. An interpretation of Aristotle's categories in the late Thirteenth Century. Leiden/Boston: Köln/Brill, 2002.

PANACCIO, Cl. Le Discours Intérieur. De Platon à Guillaume d'Ockham. París: Seuil, 1999.

TABARRONI, A. Mental signs and the theory of representation in Ockham. In: Eco, U.; Marmo, C. (eds.). On the Medieval theory of signs. Amsterdam/Philadelphia: John Benjamins Publishing Company, 1989. p. 195-224.

TACHAU, K. Vision and certitude in the age of Ockham. Optics, Epistemology and the Foundations of Semantics. 1230-1345. Leiden: Brill, 1988.

SPADE, P. V. Ockham's nominalist Metaphysics: Some main themes. En: Spade, P. V. (ed.). The Cambridge Companion to Ockham. Cambridge, USA: Cambridge University Press, 1999. p. 100-117.

SPRUIT, L. Species intelligibilis. From perception to knowledge. Classical roots and Medieval discussions. v. I. Leiden/New York: Köln/Brill, 1994.

SYNAN, E. A. (ed.). The works of Richard of Campsal. Toronto: Pont. Inst. of Med. Studies, 1968. 
VOS, A. The Philosophy of John Duns Scotus. Edinburgh: Edinburgh University Press, 2006. 